\title{
The Use of Information and Communication Technologies in Biochemistry Teaching
}

\author{
Munford,C.; Cardoso,W.; Salles,M.Mi Vinagre,F. \\ Departamento de Biofunção, ICS, Universidade Federal da Bahia
}

The gap between traditional tools for teaching and the modern multimedia languages leads us to search for new methodologies of teaching. Using the Moodle software as a Virtual Learning Environment (VLE), we give the students the opportunity to exchange experiences and research results, participate on debates and see animations. This work was meant to create a VLE and investigate its impact on the Biochemistry teaching-learning process. Besides observing students' perception and attitude towards the VLE with questionnaires and Moodle's statistical data, quantitative and qualitative studies were developed to understand the contribution of animations available in the VLE for the understanding of Biochemistry topics. The results showed that undergraduate students improved their academic results. Students mentioned that the biggest contribution of the VLE and animations was to make the study content more interesting and dynamic, motivating them to study harder. Moreover, students using only animations to study can achieve levels of knowledge similar to the ones obtained in traditional classes. Interestingly, our analysis also showed that watching animations and then attending to a traditional class makes students reach a level of knowledge that is impossible to reach only in classroom. This work demonstrates that the use of Information and Communication Technologies (ICTs) can be positive in the pedagogical processes involved in Biochemistry teaching, and they should be better spread amongst teaching institutions.

Support:CECIERJ/CEDERJ Foundation and Permanecer/UFBA

Keywords:Distance education,biochemistry education,ICT. 
This document was created with Win2PDF available at http://www.win2pdf.com. The unregistered version of Win2PDF is for evaluation or non-commercial use only. This page will not be added after purchasing Win2PDF. 